\title{
CoRPoridade E MULTITERRITORIALIDADE NA GEOGRAFIA CULTURAL: ALÉM DA DOMinAÇÃo, DA RESISTÊNCIA E DA TRADIÇÃO
}

\section{Rodrigo Ramos Hospodar Felippe Valverde ${ }^{1}$}

\begin{abstract}
Resumo: Como a Nova Geografia Cultural pode responder ao desafio de compreender a superposição física e simbólica dos fenômenos sociais? Para responder a essa pergunta, pretendemos revelar algumas das mais recentes mudanças na sua teoria, metodologia e nos seus temas. Na primeira metade desse artigo, fazemos um esforço para sintetizar as ideias fundamentais da Nova Geografia Cultural desde o seu surgimento no final da década de 1970, representando tanto os seus méritos, quanto os seus vícios de análise. Por exemplo, os estudos imateriais, as questões da intersubjetividade e a dependência excessiva do trabalho de campo estão representados nas discussões promovidas nessa etapa da síntese. A segunda metade desse artigo é dedicada às novas abordagens da Geografia Cultural, uma vez em que os temas da tradição, da resistência e da territorialidade são revistos por vários geógrafos. De acordo com essas abordagens renovadas, a Geografia Cultural deveria ser mais ambiciosa em seu esforço metodológico para conseguir lidar com um mundo vivido em múltiplas escalas espaciais. Para tornar visível esse esforço da Nova Geografia Cultural, apresentamos as ideias de corporidade e de multiterritorialidades, que nos levam a ver os fenômenos culturais de alguma forma ligados (e não mais necessariamente em oposição) à economia e à política.
\end{abstract}

Palavras-Chave: cultura, resistência, corpo, territorialidade.

\section{Embodiment and multiterritoriality in Cultural Geography: beyond domination, resistence and tradition}

\begin{abstract}
How does New Cultural Geography respond to the challenge of comprehending the physical and symbolic superposition of social phenomenas? In order to answer this question, I intend to reveal some of most recent changes in its theory, methodology and subjects. In the first half of this article, I developed an effort to synthesize the fundamental ideas of the New Cultural Geography since its beginning at the late 70's, where its merits and vices are both represented. In example, the immaterial studies, the inter-subjectivity issues and the overdependence of fieldwork are all present as part of this synthesis. The second half of this article is concerned to newer approaches to Cultural Geography, as the ideas of resistance, tradition and territoriality are reviewed by several geographers. According to this newer approaches, Cultural Geography should be more ambitious to cope with a world lived through multiple scales. In order to do so, I presented the ideas of embodiment and multiple territorialities that bring us to see culture somehow in connection (and not necessarily in opposition to) with economy and politics.
\end{abstract}

Key-Words: culture, resistance, body, territoriality.

\footnotetext{
${ }^{1}$ Graduação em Geografia pela Universidade Federal do Rio de Janeiro, mestrado em Geografia pela Universidade Federal do Rio de Janeiro e doutorado em Geografia pela Universidade Federal do Rio de Janeiro. Professor Doutor da Universidade de São Paulo e pesquisador associado da Universidade Federal do Rio de Janeiro. E-mail: rvalverde@usp.br
} 


\title{
INTRODUÇÃO
}

Don Mitchell, geógrafo inglês, tem se apresentado como um dos críticos mais contundentes da Nova Geografia Cultural, sintetizando a desconfiança que um grande grupo de geógrafos tem em relação ao desenvolvimento desse subcampo da Geografia. Para o autor, a forma pela qual a cultura é trabalhada na Geografia apenas ratifica as estratégias do consumo diante da globalização. Ainda que sua afirmação apresente um claro exagero ao generalizar os estudos de Geografia Cultural, limitar suas discussões e diminuir o rigor na análise de contribuição de outros subcampos da Geografia, é preciso conferir crédito a polêmica levantada. Em suas palavras:

\begin{abstract}
"Now everyone wants to be a cultural geographer. Cultural geographers get to study music; sex; cultural identity; the mall; tourist attractions; literature; shopping (or rather 'consumption'); race, gender and ethnicity (that is, anything but class); spectacle; representation; tropes of mobility; theme restaurants and theme parks; protest and social movements; 'nature'; and anything putatively postmodern, poststructural, postcolonial, or postpolitical. Not only is cultural geography fun, but doing it makes its practitioners look like they are doing something important, something relevant to the world we live in, for the world we live in seems to be fully, inescapably, irrevocably 'cultural'. It is no exaggeration now to say that 'culture is everything' (...). Indeed, by finding culture in everything, I will argue that geographers both draw on and reinforce a form of culturalism that is in fact helpful to, rather than a hindrance of, the project of global capitalist expansion" (MITCHELL, 2000: p.3).
\end{abstract}

Para compreender o sentido da polêmica e da ironia de Mitchell, o objetivo desse artigo é justamente conferir maior visibilidade aos méritos e vícios da Nova Geografia Cultural, refletindo um interesse que ultrapassa os limites desse subcampo e que, como revela o texto de Mitchell, gera reações por parte de toda a Geografia. Para o bem ou para o mal, a Nova Geografia Cultural parece ser capaz de ativar uma discussão ampla na Geografia, fato não tão comum ao longo de toda a história do pensamento de nossa ciência. Sempre que se cria uma polêmica tão ampla e que está é desenvolvida por um período de tempo tão largo (cerca de 15 anos), significa que o sentido de sua discussão é relevante para o desenvolvimento para além dos limites do subcampo (LÉVY, 2008).

Logo de início, é preciso responder rapidamente as acusações mais superficiais de que faltaria à Geografia Cultural um certo grau de homogeneidade e consistência teórica para que esta estivesse no mesmo nível dos outros subcampos da Geografia. Para os críticos, as diversidades temáticas e metodológicas demonstrariam a fraqueza deste subcampo, e 
justificariam as desconfianças no seu desenvolvimento. Tomamos como pressuposto que o rigor cobrado frente à Geografia Cultural se mostra contrastante com aquilo que se observa em outros subcampos: na Geografia Econômica, na Geografia Urbana e na Geografia Agrária, por exemplo, a diversidade de temas, de ideologias e de métodos é tão clara quanto aquela que se observa na Geografia Cultural. Acreditamos que, se há variedade de temas e métodos na Geografia Cultural, tal variedade deveria ser celebrada como parte de um processo necessário de renovação e diversificação do conhecimento geográfico, permitindo inclusive que os antigos modelos explicativos que balizaram a Geografia possam ser, de algum modo, problematizados. A preocupação metodológica da Geografia Cultural se mostra inclusive mais clara do que em outros subcampos, uma vez que a definição dos termos do trabalho de campo ou a identificação do grupo social, ou ainda os limites da relação intersubjetiva entre o pesquisador e o objeto, são colocados em questão (DUCAN; DUNCAN, 2004; JACKSON, 2000).

Para que essa leitura seja pertinente, é igualmente necessário aceitar que a Geografia Cultural ultrapassa o utilitarismo (ou a sua denúncia) que marca boa parte da Geografia. A pergunta "qual é a utilidade da geografia cultural?" deve então ser respondida pelo estudo da diversidade de representações, identidades e simbolismos que se desenham em um mundo no qual o Estado-Nação diminuiu o seu controle sobre o domínio da cultura. Como veremos a seguir com mais detalhes, entende-se que novas paisagens, lugares e territorialidades ganham sentido no mundo atual, conferindo inclusive ao indivíduo um novo poder de ação. Sob os limites da influência do pensamento crítico na Geografia, é possível no máximo considerar que a própria ideia de cultura pode ser uma importante alavanca para a economia e para a política, ao diminuir os conflitos pela dominação. Porém, o mais difundido na Geografia Cultural seria afirmar que o mundo não pode ser explicado apenas por um conjunto de respostas objetivas, funcionais e universais: por princípio, temos o reflexo de transformar os modelos gerais ao qualificá-los pelos nossos valores. Nesse sentido, se há a necessidade de justificar a Geografia Cultural pela sua utilidade, seria preciso reconhecer que os estudos culturais podem referenciar e aumentar a eficiência da política e da economia (DUNCAN; DUNCAN, 2004).

Para os fins desse artigo, tomamos como referência os desafios para o desenvolvimento da chamada Nova Geografia Cultural, em detrimento daqueles trabalhos desenvolvidos sob os termos estritos do pensamento de Franz Boas e de Carl Sauer. Tal escolha possui uma dupla 
justificativa: em primeiro lugar, há uma limitação de espaço dentro do artigo que impede uma releitura completa da Geografia Cultural, fato que exige um corte analítico; em segundo lugar, os trabalhos da Geografia Cultural Tradicional já foram amplamente debatidos em seus méritos e vícios pelos autores da Nova Geografia Cultural, como se observa na obra de Cosgrove, Duncan e Mitchell, entre outros. Esses autores se encontravam sobretudo ligados à Geografia Inglesa e Norte-Americana e, a partir do final dos anos 1970, inauguraram uma forma de investigação que buscava uma ideia de cultura fundamentalmente diferente. $\mathrm{Na}$ atualidade, o que mais chama atenção dos geógrafos, sejam esses simpáticos ou não a essa forma de trabalho, é justamente a rápida difusão dessa Nova Geografia Cultural, assim como os limites e vícios de sua avaliação. Por último, essa escolha parece ser justificada também de forma derivativa: na medida em que tantas pessoas se esforçam para ampliar ou restringir o debate da Nova Geografia Cultural dentro da Geografia como um todo, o debate de suas ideias se mostra interessante a um amplo público.

\section{MATERIAIS E MÉTODOS}

A produção bibliográfica mais recente dos autores que animaram o debate dos méritos e dos vícios da Geografia Cultural serviu de fonte primária para o desenvolvimento da metodologia desse trabalho. Entre outros, buscamos as obras de Tuan, Cosgrove, Duncan, Mitchell, Jackson e Claval, que, em grande parte, tem servido tanto como defensores dos estudos culturais na Geografia, quanto como aqueles que apresentam as suas falhas e fraquezas. Tal escolha não foi fortuita, pois, nos últimos 30 anos, a citação desses autores tem marcado quase todos os trabalhos de Geografia Cultural, em todo o mundo. Seguimos de início os limites de uma periodização comumente aceita: a ideia de que a Nova Geografia Cultural surgiu no final da década de 1970 e se desenvolveu com particular velocidade a partir dos anos 1990 em todo o mundo. Nesse sentido, ao explorar a obra desses autores, tomamos conhecimento dos temas e questões que inspiraram a rápida expansão da Nova Geografia Cultural. Esta é justamente a tarefa a ser cumprida na primeira parte do desenvolvimento do presente artigo: sintetizar as vias desenvolvidas na Nova Geografia Cultural. Por escolha analítica, não faremos uma análise por autor, uma vez que diversos argumentos são compartilhados por esses. É preferível então buscar os temas e opções metodológicas que marcaram o subcampo da Geografia. 
Em seguida, na segunda etapa desse artigo, lançamos luz sobre a discussão de alguns referenciais teóricos mais recentes, como aqueles relativos à corporidade (embodiment) e à multiterritorialidade. Tais referenciais têm sido desenvolvidos a partir da compreensão de que as formas mais repetidas para o desenvolvimento da Nova Geografia Cultural se mostram pouco nuançadas e com pequeno poder explicativo diante de fenômenos mais atuais. Ambos tem sido frequentemente utilizados como base para o desenvolvimento de artigos em periódicos especializados, como é o caso do Journal of Social and Cultural Geography, Progress in Human Geography, Géographie et Cultures, Transactions of the British Geographers, entre outros disponíveis, apesar de pouco discutidos na Geografia Cultural brasileira. Buscamos esses novos referenciais como parte de um movimento de renovação da Geografia Cultural que almeja ser capaz de dialogar com o mundo globalizado além dos limites de seus estudos mais frequentes, marcados pela ideia de resistência, de tradição e de dominação. Dessa forma, a ideia é demonstrar que a Geografia Cultural pode trabalhar em múltiplas escalas e com fenômenos superpostos no espaço, desafios normalmente negligenciados nos últimos 30 anos. Esperamos assim estimular novas linhas de investigação e contribuir para a diminuição do descompasso entre as discussões que animam esse subcampo dentro e fora do Brasil.

\section{Os vícios de análise da Geografia Cultural contemporânea}

Dois modelos tem marcado o desenvolvimento da Geografia Cultural nos últimos 30 anos. Cada um desses modelos apresenta diferentes contribuições, usa escalas de avaliação que são distintas e escolhe trabalhar com referências metodológicas oriundas de outras ciências sociais. O primeiro desses modelos se refere à resistência do lugar criado pelos grupos sociais (DUNCAN; DUNCAN, 2004; TUAN, 1983), enquanto o segundo modelo trabalha com os espaços da cultura como elemento de dominação social (ATKINSON; COSGROVE, 2000; MITCHELL, 2005). Pela repetição, esses dois modelos tenderam a apresentar vícios de análise que merecem ser considerados em qualquer estudo crítico da Geografia Cultural, apesar desses vícios raramente serem lembrados.

Sem dúvida alguma, a forma mais consolidada para o desenvolvimento de trabalhos de Geografia Cultural depende do reconhecimento dos grupos sociais e dos seus jogos de apropriações e representações espaciais. Por grupo social, entende-se normalmente um 
grupo de indivíduos que possuem características homogêneas (étnicas, tradicionais, classe social, bairro etc.), caracterizando uma identidade em comum que seria referenciada por um lugar. Quanto mais forte for o laço coesivo desse grupo social, escorado na antiguidade, no tradicionalismo e nas distinções em relação à vida moderna, mais claro parece o interesse da Geografia Cultural pelo seu estudo. Acredita-se que esses grupos sociais sobrevivem frente às ameaças da vida moderna em parte devido ao lugar, que seria compreendido nos termos sugeridos por Tuan:

"O que começa como espaço indiferenciado transforma-se em lugar à medida que o conhecemos e o dotamos de valor. (...) A partir da segurança e estabilidade do lugar estamos cientes da amplidão, da liberdade e da ameaça do espaço, e vice-versa. Além disso, se pensamos no espaço como algo que permite movimento, então lugar é pausa; cada pausa no movimento torna possível que localização se transforme em lugar" (TUAN, 1983: p.6).

Nos termos dessa perspectiva, o lugar não depende diretamente do domínio material ou do planejamento impessoal realizado nos fóruns públicos do Estado. Parte-se do pressuposto de que o lugar é derivado de valores e significados que, antes de qualquer materialização, são relativos às ideias dos grupos sociais. Um espaço público criado e gerenciado pelo Estado pode ter uma grande diversidade de equipamentos para estimular a vida social (árvores, bancos, iluminação, brinquedos para as crianças, quadras esportivas etc.) e, na prática, não ser apropriado por nenhum grupo social. Nesse caso hipotético, não existiria nenhuma familiaridade, intimidade ou narrativa que pudesse ser ligada a esse espaço. Em contrapartida, existem áreas que não possuem nenhum preparo para a vida social por parte do Estado, mas que ganham narrativas e significados diferentes daqueles que foram planejados, tornando-se um lugar. Os rituais encenados pelos cultos afro-brasileiros ilustram essa situação: a princípio, as esquinas das grandes cidades ou os terrenos baldios apropriados não possuem valor simbólico ou material para a maior parte da população. Porém, os seguidores desses cultos são capazes não apenas de atribuir significado religioso a um espaço que não possui valor material, mas também de enxergar diferenciações (sagradoprofano, diferentes entidades, sinais territoriais, diferentes grupos religiosos etc.) nessa mesma área (MELLO CORRÊA, 2005).

Ao evocar o lugar como criador de uma pausa no movimento contínuo que define o espaço e suas dinâmicas sociais modernas, Tuan (1983) atribuiu força à tradição. De acordo com a visão do autor, o poder de homogeneização do espaço na Modernidade pode até ter alcançado a maior parte do mundo material, mas não alcançou jamais uma redução dos 
valores, das representações e dos significados. Aqueles fenômenos que eram considerados como resquícios do passado não desapareceram, mesmo quando confrontados pela quebra da estabilidade das formas materiais, pela diáspora e pela transformação das condições de sobrevivência. De alguma maneira, uma parte dos modos de vida tradicionais teria permanecido viva nas sociedades modernas.

Por essa razão, o apelo aos lugares dos grupos sociais na Geografia Cultural tendeu a ser tratado também como um ato direto e consciente de resistência à modernidade e de defesa da identidade. Seguindo esse raciocínio, os agentes desses grupos sociais estariam dispostos a pensar em como manter sua ligação com a terra, em como manter estável o seu modo de vida, em como preservar seus valores e controlar a influência de pessoas de fora em seus domínios. Os técnicos do Estado e as grandes corporações representariam então o perigo do desaparecimento do grupo social e de seu modo de vida, devido as enormes diferenças de recursos e de capitais. Caberia então ao grupo social dar preferência à manutenção do que ainda existiria de autêntico em seu modo de vida, pois os contatos entre esses modos de vida tradicional e moderno tenderiam por definição a ser benéfico apenas ao segundo. Sempre que possível, o geógrafo que seguia essa forma de trabalho deveria revelar a riqueza simbólica desse grupo social, assim como a insensibilidade e pobreza simbólica dos fenômenos modernos.

Os aportes de técnicas de campo e de limites de investigação da Antropologia marcam essa forma de trabalho da Geografia Cultural. Seria preciso revelar o lugar por trás da materialidade e da dominação dos espaços da modernidade. Para tanto, seria preciso trabalhar dentro dos limites da microescala dos grupos sociais. A experiência cotidiana das pessoas de um grupo social seria decisiva na definição do lugar: quanto mais tempo esses indivíduos estivessem nessa área e quanto mais homogênea fosse a origem desses indivíduos, mais forte e mais claro seria o lugar. Ao conferir voz e força ao reconhecimento dos valores e dos sentimentos de um grupo social e de seu lugar, tenderíamos por vício de análise a trabalhá-los isoladamente, como se esses grupos não estivessem ligados ao restante da sociedade por intermédio do trabalho, do ensino etc. (HOEFFLE, 2007; TUAN, 1983).

Também buscaríamos a maior fidelidade o possível para com a visão dos grupos sociais, diminuindo qualquer leitura crítica que pudesse ser estabelecida em suas práticas. Por princípio, essa Geografia Cultural trabalharia dentro dos limites do relativismo, que 
estabeleceria a necessidade de compreender o modo de vida daquele grupo e evitar comparações e modelos pré-definidos para avaliá-los. O rigor na coleta de entrevistas, no detalhamento das características e valores do lugar, a preocupação com as possíveis consequências, entre outras práticas, deveriam compensar a ausência de generalizações, de dados técnicos ou qualquer esforço comparativo.

O segundo modelo de análise desenvolvido tradicionalmente pela Geografia Cultural se encontra no polo oposto aquele do grupo social. Falamos aqui da lógica de dominação simbólica e/ou da servidão voluntária, na qual se admite que grupos hegemônicos criem um sistema cultural que reforça seus mecanismos produtivos e de poder. Por essa lógica, seria preciso diminuir os conflitos que se estabelecem tanto pela quebra ou relativização dos laços tradicionais, quanto pela abertura de um sistema de poder democrático que permitem manifestações e transformações sociais. Autores como Mitchell (2000) tem argumentado que a cultura seria uma composição de ideias que permitiriam diminuir o uso da coerção para gerar um sentimento de coesão. Em outras palavras, a cultura seria uma poderosa ideia para dominar e influenciar outras pessoas.

Do ponto de vista geográfico, a questão seria então aproximar artificalmente nomoespaços, tal qual definidos por Gomes (2002), dos lugares imaginados, criados e mantidos pela população. Se a base de um nomoespaço é inicialmente fria, distante dos laços emotivos, da história, da tradição, da etnia e das identidades em geral, seria preciso referenciar esse espaço por uma narrativa minimamente controlada e referenciada pelo poder hegemônico. De acordo com diversos autores, é nesse contexto que se reforça o nacionalismo, o ensino público, as instituições culturais dos Estados, a ideia de arte nacional, o patrimônio histórico, o monumentalismo entre outros fenômenos da Modernidade.

Segundo Corrêa (2010) o monumento ao Rei Vittorio Emanuelle II, localizado em Roma, simbolizaria o esforço de criação de um lugar para nação italiana recém-unificada. Em suas palavras:

"Grandioso, com três níveis, o monumento em estilo neo-clássico desenvolve uma narrativa heróica da história italiana. Além da estátua equestre do rei estão representados, em forma de alegorias, o passado imperial, a unificação italiana, o caráter secular do Estado italiano, em oposição à presença próxima do Vaticano, os soldados italianos mortos em diversas guerras, e as cidades e regiões italianas. Considerado simbolicamente como o 'altar da nação', o monumento constitui-se em exemplo de retórica, isto é, 'técnicas de argumentação visando convencer e persuadir no espaço público urbano [...] fortemente aliadas à arte da memória (Atkinson e Cosgrove, 1998, pp. 31)' (CORRÊA, 2010). 
Dito de forma mais clara, nos termos desse olhar, a cultura não seria apenas um reflexo das tradições ou das afinidades, mas seria também produzida pelo poder público e pelos agentes privados. Com o avançar das comunicações, das trocas e das estratégias de dominação, a cultura estaria migrando de seu sentido original, vinculada aos grupos sociais, para o polo do poder e da dominação. Antes mesmo que um indivíduo pudesse desenvolver suas personalidade e que recebesse a influência do seu grupo social, os meios de comunicação e a socialização das escolas realizariam uma homogeneização. Por essa perspectiva, não seriam os méritos artísticos, o apelo popular ou a antiguidade de uma prática social que garantiriam a cultura.

Há polêmica dentro desse modelo sobre os limites da dominação simbólica realizada pelo Estado e pelas corporações. Alguns seguem a visão pessimista trazida da Escola de Frankfurt através da revisão das obras de Walter Benjamin, Theodore Adorno, Max Horkheimer, entre outros. Por essa perspectiva, as apropriações e filtragens das referências culturais realizadas tanto pelo Estado quanto pelas corporações seriam capazes de diminuir as capacidades de interpretação e de imaginação e, nesse processo, extinguir qualquer possibilidade de transformação real. Outros são mais moderados na avaliação e buscam em autores variados como Michel Foucault, Henri Lefebvre, Herbert Marcuse e Jurgen Habermas as bases para a superação da dominação e o desenvolvimento de uma nova política. No entanto, há consenso de que a influência dos poderes hegemônicos se estenderia muito além dos limites da materialidade e da produção.

Normalmente, o que se revela por esse tipo de perspectiva é mais um espaço da cultura do que propriamente um lugar, no sentido previsto por Tuan, entre outros autores. Falamos de um espaço que carregaria os símbolos, os valores e as cores escolhidas pelo Estado e pelas corporações como base de referenciamento cultural (ATKINSON; COSGROVE, 1998). Ainda que essas referências possam ser reconhecidas e utilizadas pela população, esses espaços da cultura não necessariamente se tornam lugares. Nota-se uma alteração significativa pelo fato de essas referências culturais terem sido retiradas do seu contexto original, da sua área de influência e dos grupos sociais que lhes conferiam sentido. Por exemplo, as estátuas erguidas pelo Estado para honrar os heróis da pátria não possuiriam então a mesma força coesiva de um totem levantado por um grupo indígena, pois a memória evocada e o lugar de referência não seriam experimentados cotidianamente. Os museus nacionais colocados como referência da cultura não substituiriam perfeitamente a proximidade dos saberes 
locais e de sua difusão, funcionando mais como um inventário de referências tão desconexas quanto aquelas referentes aos ribeirinhos do Rio Amazonas e os gaúchos dos Pampas.

Ao produzir e difundir um sistema cultural artificial cujo objetivo é homogeneizar e diminuir os conflitos, os trabalhos de Geografia Cultural costumam destacar as falhas, os exageros e os autoritarismos desse sistema. Muitas vezes, o seu espaço é avaliado como um simulacro de lugares: ao invés de representar e qualificar os valores e sentimentos de um grupo social, tal simulacro tentaria criar o sentimento e valor que qualificariam o grupo social. Na melhor das hipóteses, de acordo com os defensores dessa perspectiva, esse lugar-simulacro seria capaz de oferecer uma série de referências culturais desconexas que serviriam de referência para a vida cotidiana. Todavia, a origem externa dessas referências muitas vezes se chocaria com as experiências e necessidades do grupo social, o que limitaria o seu poder de coesão. Aos poucos, com a estabilização desse sistema e a redução dos investimentos públicos e privados na sua manutenção, tais espaços-simulacro perderiam a sua força e, consequentemente, o seu sentido original.

Por razões como essa, o esforço de criação e manutenção de uma narrativa nacional e de um sentimento de coesão através de feriados cívicos, desfiles, feriados, monumento e a designação de heróis da pátria nem sempre se mostra duradouro. Corrêa (2010) destacou como a memória dessa narrativa nacional se decompõe e o lugar criado perde o seu sentido e se deteriora. Os geógrafos culturais que trabalham nessa perspectiva tentam demonstrar então como essa macroescala dos valores esconde estratégias de dominação que não são eficientes como força coesiva, mas são suficientemente fortes para relativizar o papel dos lugares, pois esses poderiam funcionar como forças que fragmentariam o espaço.

O papel do geógrafo seria então aquele de denunciar esses mecanismos de dominação ou então cartografar poderes que se desenham a partir de valores e que, muitas vezes, se projetam como representações imateriais. Seria preciso reconhecer nas instituições públicas e nas telecomunicações um esforço de sinalização das culturas que seria limitador da interpretação do real. Para tanto, esses geógrafos buscariam leituras na semiótica ou na ciência política que Ihes permitissem interpretar com mais clareza a transfiguração das culturas tradicionais e populares.

Diversos problemas derivam dos limites desses dois modelos que dominaram a Geografia Cultural nos últimos 30 anos. O primeiro problema se refere ao "esquematismo" dos objetos de estudo e das abordagens. Tal "esquematismo" se configura no momento em que se é 
possível rapidamente atribuir os casos trabalhados dentro dos modelos e dos métodos, de forma que a própria riqueza da descrição fique em segundo plano. Quando o caso abordado é tão perfeitamente substituído pelo modelo de análise, é possível questionar a necessidade da realização do estudo de caso, pois não há ganho real à Geografia. De um modo geral, na Geografia Cultural desenvolvida nos últimos 30 anos, parece ser obrigatória a escolha de um objeto de estudo que se encontra em um grupo social tradicional e "puro" ou em uma estratégia de dominação do poder hegemônico através de um sistema simbólico. Os meiostermos e nuances não são comuns, assim como os estudos que fujam ao esquema. Nesse processo, a renovação é pequena.

Nas palavras de Duncan e Duncan:

\begin{abstract}
"The question of continuity over space and how it is achieved despite the inherent unboundedness and historical dynamism of cultures is a key issue in the quest to understand the coherence of cultures. The world history of migration of people, goods, and ideas around the globe, transculturation and the increasing strength of transnational networks which contribute to the instability of the spatial dynamics of cultures, and the internal heterogeneity of even the most spatially isolated cultures are the background upon which any theory of cultural stability and coherence must be set. It would be useful to introduce more spatial complexity and spatial dynamism into the study of culture in terms of countering popular associations of culture with territory-the sacred blood-culture-nation-state nexus. Actor-network theory, with its objective of tracing complex alliances and entanglements across space and through time, may provide a useful framework" (DUNCAN; DUNCAN, 2004: p.398).
\end{abstract}

Um segundo problema significativo se refere à monoescala dos espaços e lugares. Muitos indivíduos vivem influenciados por mais de um lugar e pelo espaços da cultura do poder hegemônico. É comum inclusive que sejam capazes de se filiar simultaneamente ao espaço e ao lugar. Ainda que estejam completamente contidos pelo lugar, esses indivíduos estarão necessariamente sob a influência dos poderes hegemônicos que se projetam sob aqueles limites. Ainda que, dentro dos dois modelos colocados, haja apelo à outra escala, tal apelo serve apenas de contraponto ao argumento que é apresentado. Por exemplo, quando se toma uma praça que conta com monumentos para evocar a narrativa nacional, pode ser lembrado que certos grupos sociais não são integrados a essa narrativa, assim como os seus lugares. Também seria possível argumentar que essa praça está desconectada da vida cotidiana daqueles que vivem próximos a ela. Porém, tais lembranças não significam que a escala do trabalho mude: ela continua focada unicamente na escala do nacional e do seu sistema de referências culturais. O mesmo é válido no sentido contrário. O modo pelo qual 
um grupo social se apropria material e imaterialmente de um espaço para criar o seu lugar define uma microescala que, para todos os efeitos, seria a única sob o foco de análise. Ainda que seja evocado o espaço da cultura engendrado pelo grupo hegemônico, este serve apenas para valorizar ainda mais a resistência do grupo social.

O terceiro problema se refere a quase exclusividade do tradicionalismo na escolha de temas e na definição dos objetos de estudo. Para fortalecer o discurso identitário e o lugar, a preferência na definição dos temas da Geografia Cultural parece ter sido concedida a objetos que encontram suas referências distantes da modernidade ou, pelo menos, diferentes da lógica capitalista. Camponeses, indígenas, grupos étnicos minoritários, migrantes, moradores de favelas ou de bairros populares, religiosos, entre outros casos possíveis, dominam o universo da Geografia Cultural. Por consequência, grupos que fogem ao discurso da identidade ou que se escoram em práticas capitalistas ou modernas são observados como desprovidos de cultura significativa.

O quarto problema se refere à omissão dos geógrafos culturais frente aos conflitos materiais e simbólicos entre grupos sociais e seus lugares. Pela forma mais frequente de investigação, os grupos sociais e seus lugares são opostos aos poderes hegemônicos, mas não a outros grupos sociais. Porém, pelo fato de uma mesma área poder ser consolidada em lugar para diferentes grupos sociais, é necessário conceber os conflitos que se constroem nessa escala. É isso que ocorre, por exemplo, no caso do Largo da Carioca, na cidade do Rio de Janeiro, ou no caso do Largo da Sé, na cidade de São Paulo. Camelôs, artistas populares, grupos religiosos, partidos políticos tentam garantir a exclusividade ou a dominância sobre essa área (VALVERDE, 2007 e 2009). Apesar dos exemplos serem abundantes nas grandes cidades, o que foi mais comum dentro da Geografia Cultural teria sido a manutenção dos limites analíticos dos dois modelos citados.

O quinto problema a ser colocado é relativo à forma pela qual o indivíduo é pensado. De um modo geral, toma-se o indivíduo como dotado de uma identidade coerente e, normalmente, vinculada a um modo de vida tradicional. Esse indivíduo poderia ser confundido com qualquer outro dentro do seu grupo social, pois supostamente a sua identidade não estaria ligada a um processo de escolhas individuais. O problema se revela no momento que compreendemos que as sociedades modernas ampliaram suas redes técnicas (transportes, comunicação, produção etc.), ao ponto que mesmo os mais isolados grupos tradicionais foram levados a tomar contato com outros modos de vida. Nesse processo, de acordo com 
Hall (2000), a formação da identidade passa a ser sempre influenciada por uma variedade de culturas. Dito de forma mais clara, no período contemporâneo, a identidade é também um produto do indivíduo, e não apenas do grupo social ou do Estado. Por consequência, os limites simbólicos e materiais dos lugares são alterados.

O último problema a ser lembrado seria aquele de uma diminuição da materialidade nas análises (JACKSON, 2000). Tal diminuição seria realizada por intermédio do apelo ao imaterial, que foi inovador nos anos 70 e 80, ao sofrer a influência da Antropologia, mas que se tornou um vício de análise quando desprezava o aspecto material, econômico e político dos grupos sociais. Acreditamos que discutir cultura e lugar não deveria ser sinônimo de uma existência cujo sentido dependesse apenas do imaterial.

Para ultrapassar os limites desses dois modelos, tem se desenvolvido algumas alternativas para a Geografia Cultural nos últimos dez anos. Referimos-nos aos estudos do corpo, das multiterritorialidades e a diversificação dos objetos de estudo. Porém, essa novas vias ainda carecem de uma melhor sistematização e de compreensão dos seus limites de investigação. Tentaremos apresentar esses novos elementos a seguir.

\section{Corporidade e multerritorialidade - o limite da subjetividade e o desafio das escalas}

\section{na Geografia Cultural}

Recentemente, discute-se inovação temática e metodológica na geografia cultural através das ideias de embodiment, que, aqui, vai ser traduzida como corporidade, e de multiterritorialidade. Entende-se a ideia de corporidade tal qual Cresswell a definiu:

\footnotetext{
"The process whereby the individual body is connected into larger networks of meaning at a variety of scales; the production of social and cultural relationships through and by the body simultaneously with the 'making up' of the body by external forces" (CRESSWELL, 1999: p.176).
}

Mais precisamente, a corporidade indicaria não apenas a questão da identidade de um grupo social e sua habilidade de imaginar e/ou construir lugares, mas também um filtro subjetivo e quase individual que cada um poderia estabelecer em relação a diferentes limites espaciais. Um exemplo é aquele exposto por Cresswell, ligado às mulheres moradoras de rua e o uso do corpo como meio de sobrevivência, expressão e manifestação, obtendo diferentes resultados de acordo com os grupos com os quais interagem no espaço público. Devido as suas diferentes classes sociais de origem, raça, religião, nível educacional, vícios, 
entre outros aspectos, tais moradoras de rua e seu uso do corpo não podem ser reduzidos a um mesmo grupo identitário, apesar de algumas semelhanças serem observadas em suas atividades direcionadas à sobrevivência. De acordo com essas características variáveis, os lugares que criam e os espaços de referência vão mudar, assim como o impacto dessas pessoas nas dinâmicas da área em questão. Nas palavras de Crouch:

"Taking a non-representational theory approach, space ceases to be only objective, contextual and metaphorical. Place becomes the material of popular culture which is worked, reworked and negotiated. (...) popular culture is a product of popular activity which people make themselves, using available resources. Popular culture is made and remade through what people 'do', a process rather than a product. Place becomes understood as something through which and with which lives are lived and identity and myth made" (CROUCH, 2010: p. 64).

Nota-se igualmente nessa perspectiva um convite à discussão da multiterritorialidade e à reflexão multiescalar. Nesse artigo, acompanhamos a definição de territorialidade que foi apresentada por Sack (1986). O autor salientou que a territorialidade humana não precisa seguir os limites que são aplicados na ecologia, pois as estratégias humanas tem objetivos e métodos mais variados. Sack destacou inclusive que a territorialidade humana vai além do aspecto material ou da estabilidade absoluta dos limites físicos do território. Segundo Sack:

"Territoriality is best understood as a spatial strategy to affect, influence or control resources and people, by controlling área; and, as a strategy, territoriality can be turned on and off. In geographical terms it is a form of spatial behavior" (SACK, 1986: p.1-2).

Seguíssemos os limites estritos da Geografia Cultural dos grupos sociais, a forma mais frequente de seu desenvolvimento seria considerar a projeção material e simbólica dos valores desse grupo social homogêneo sobre a base espacial do poder hegemônico. Do ponto de vista cultural mais defendido, apenas o lugar criado pelo grupo social seria dotado de significado, enquanto o espaço do poder hegemônico seria, via de regra, vazio de real poder simbólico e necessariamente distante das representações populares. Nesse contexto, por mais que se estabeleçam duas bases espaciais sobrepostas, a saber, aquelas do grupo social e do poder hegemônico, o desenvolvimento metodológico da geografia cultural é realizado sob o foco do lugar e do seu significado. Tudo aquilo relativo ao espaço é discutido como um contraponto negativo, vazio de valor cultural legítimo e autoritário em relação ao grupo social. A multiescalaridade e multiterritorialidade seriam então bastante limitadas dentro desses termos. 
Para que a perspectiva fosse de fato multiescalar e multiterritorial, seria preciso relativizar tanto o peso do lugar do grupo social, quanto aquele da base material hegemônica. Mais do que um simples reconhecimento de um lugar fechado em si mesmo e dependente da pureza e da homogeneidade do grupo social, a corporidade nos indica que as experiências de um indivíduo são mais fragmentadas e variadas do que seria possível o jogo entre oposições binárias (estado-grupo social, espaço-lugar, hegemônico-alternativo, economia-cultura etc.). É preciso então reconhecer que o romantismo filosófico que sustentou o desenvolvimento da Geografia Cultural possui limites que diminuem o registro das multiterritorialidades. Para que estes registros passem a ser valorizados, é preciso entender que todos estão referenciados por múltiplas territorialidades, materiais e imateriais, identitárias ou não, voluntária ou involuntariamente (DUNCAN; DUNCAN, 2004).

Entendemos multiterritorialidade nos limites em que esta ideia foi apresentada por Haesbaert: trata-se da aceitação de que diversas estratégias são definidas para influenciar comportamentos, gerenciar acesso às áreas e controlar seus recursos. Não é suficiente definir um grupo social de referência, seus valores e sua área de influência para que a Geografia Cultural tenha cumprido as suas responsabilidades. Mesmo a intervenção mais autoritária o possível é transformada pelas representações que se sobrepõe a ela, ainda que essas sejam imateriais. A tarefa da Geografia Cultural prevista na perspectiva da corporidade sugere então que as territorialidades alteram as formas como vivenciamos o espaço por um jogo de influências, um campo de forças continuamente renovado.

Talvez, ainda seguindo a discussão de Haesbaert, esse princípio da multiterritorialidade tenha se tornado mais evidente a partir do momento que algumas referências essenciais do período histórico da Modernidade tenham sido relativizadas. De fato, o contexto definido pela corporidade e pela multiterritorialidade parte de alguns pressupostos presentes na discussão da Pós-Modernidade, tal qual o hibridismo cultural, a redefinição do indivíduo, a diversificação das identidades e a transformação da política. Dito de forma mais clara, essa perspectiva da Geografia Cultural toma como ponto de partida que os modelos que previam os embates entre Estado, corporações e indivíduos dentro de uma hierarquia estável não são mais absolutos.

Nas palavras de Haesbaert:

"Multiterritorialidade inclui assim uma mudança não apenas quantitativa pela maior diversidade de territórios que se colocam ao nosso dispor (ou pelo menos das classes mais privilegiadas) - mas também qualitativa, na medida em que temos hoje a possibilidade de combinar de uma forma 
inédita a intervenção e, de certa forma, a vivência, concomitante, de uma enorme gama de diferentes territórios" (HAESBAERT, 2005: p.6783).

É importante salientar que tais estratégias podem ter finalidades muito distintas e se sobrepõem umas as outras, utilizando escalas diferenciadas. Entre o material e o imaterial, uma mesma área pode receber diferentes representações culturais e formas de apropriação. Tal sobreposição não é insignificante - no que tange a perspectiva da multiterritorialidade, seria preciso reconhecer as influências mútuas que se realizam. Nesse momento, é preciso considerar que essas influências não ocorrem apenas no sentido da influência dos grandes poderes e das grandes escalas sobre as menores. Nos termos definidos por Haesbaert, esse jogo de influências se desenha em mais de um sentido. Ainda que, por definição, algumas dessas territorialidades possam não ter finalidades conflitantes diretamente, na prática tais territorialidades afetam e/ou alteram as outras.

Sob uma mesma praça, se observa a política de patrimonialização do poder público, com as suas estátuas e apelo aos heróis da pátria. A escala geográfica trabalhada tem amplo escopo, pois integra essa área à nação ou a identidade de uma cidade, por exemplo. Simultaneamente, se observam as estratégias de agentes econômicos para ter maior controle físico e simbólico sobre essa área, como ocorre quando os restaurantes colocam suas mesas sobre o passeio público, ou quando cercam a área com plantas e outros recursos, ou quando apresentam seus negócios através de galhardetes, letreiros ou placas. A escala utilizada revela uma área de influência que é menor do que aquela da patrimonialização, mas que vai além da área imediatamente vizinha aos restaurantes. Deseja-se atrair um público amplo da cidade, talvez alterando e sendo alterada pelo próprio sentido da territorialização do poder público: ao romper com a vivência da política e instituir ainda que temporariamente a sociabilidade como referência de sua territorialidade, o resultado é necessariamente um meio termo entre ambas. Por último, a presença de grupos sociais, mais ou menos tradicionais, nessa mesma praça também modifica o campo de forças das territorialidades descritas. Ainda que a escala de ação desses grupos estivesse ligada ao limite de um lugar, da vivência cotidiana, os efeitos da sua existência podem se estender mais além. Se essa praça for apropriada por grupos de jovens skatistas, ou pela população de rua, entre outros casos possíveis, mais uma vez se estabelece um rompimento temporário das escalas maiores que pode enfraquecer o seu domínio simbólico. Os heróis da pátria podem ser contrapostos por outras referências, mais próximas da vivência desses grupos. O engajamento e a finalidade política previstos na escala do espaço da cultura 
podem ser substituídos por uma postura que valoriza as necessidades dos grupos sociais. Ainda mais significativo seria compreender que uma pessoa que desconhecesse o jogo dessas territorialidades na praça seria capaz de apreender apenas uma parte dos seus símbolos e significados, dependendo das suas próprias referências culturais.

Por definição, essa praça hipotética que foi descrita seria multiterritorial, dependeria da corporidade para ser apropriada e compreendida de diferentes formas e se encontraria conectada a várias escalas analíticas. Suas oportunidades de estudo seriam então variadas e deveriam ser enunciadas pelo pesquisador: não haveria mais a pretensão da totalidade do estudo e nem mesmo do esgotamento da geografia que poderia ser derivada dessa área. Seria preciso definir as escalas que são investigadas, o foco da análise e o método que foi escolhido. Também seria preciso compreender os próprios limites e problemas da investigação e aceitar que, ainda que esse mesmo objeto seja tomado por outro pesquisador, o resultado obtido poderia ser outro, devido às diferenças nas interpretações.

Um primeiro problema que emerge dessas novas formas de trabalho da Geografia Cultural se encontra no questionamento se esses territórios seriam entendidos por uma base concreta mais ou menos regular ou se tais territórios seriam apenas receptáculos temporários da vida social. Ao conferir maior dinamismo às representações e às apropriações, a Geografia Cultural carrega o desafio de demonstrar que a imaterialidade não enfraquece o debate territorial. De acordo com as formas mais recentes da Geografia Cultural, se há descontinuidade espacial, flutuação dos limites e sobreposição de identidades, isso não enfraquece o laço com o mundo concreto. Segundo esse olhar, não é o título de posse, a antiguidade do domínio ou o controle de acesso exclusivo que garantem a importância da territorialidade. Por exemplo, uma área controlada e definida como exclusiva pode ser vazia de sentido para a vida social, se tornando apenas um receptáculo vazio. Além disso, para essa Geografia Cultural, o mais importante é que ainda que exista maior fluidez na definição dos limites concretos e de suas consequências dentro dessas territorialidades, os fenômenos sociais ainda são qualificados pelas suas localizações. Com isso, o mundo concreto não é apenas o pano de fundo de uma trama social qualquer: ao contrário, a localização desse fenômeno ajuda a explicá-lo, assim como o seu impacto sobre o restante do mundo. Para essa Geografia Cultural, é preciso compreender que o território e a territorialidade não são definidos pelo controle do acesso do receptáculo físico, mas sim pelas suas múltiplas capacidades de qualificação e significação dos fenômenos. 
Um segundo problema seria advindo dos limites da subjetividade como base de interpretação. Ao relativizar a importância da identidade e colocá-la em contato com uma série de outros modos de vida, convivendo e competindo por uma mesma área, alguns críticos manifestam suas preocupações em relação à perda daquilo que caracterizava a Geografia Cultural nos últimos anos. Outros também se mostram reticentes em relação a uma suposta confusão (ou conflito) de narrativas dentro dos trabalhos. Há ainda quem cite a diminuição da escala parece exagerada, chegando aos limites da individualidade e diminuindo a relevância do trabalho de Geografia Cultural. Sem desprezar essas críticas, é preciso compreender que a intersubjetividade é um desafio inerente a todos os trabalhos das ciências sociais, por mais que o tema possa se encontrar fora dos limites dos fenômenos culturais. Nesse sentido, o que protege um trabalho da arbitrariedade ou dos julgamentos de valor é a definição metodológica e a honestidade no uso das fontes, entre outros elementos possíveis. Ainda mais importante é considerar que ao lidarmos com a figura do indivíduo e sua importância para as territorialidades, preenchemos uma lacuna há muito deixado vaga na Geografia. Para tanto, foi preciso diferenciar a formação da personalidade do indivíduo de um processo mais amplo, no qual este indivíduo abordado pela Geografia Cultural assume papéis sociais e modos de vida que podem ter impacto em escalas espaciais diferentes daquela referente à sua sobrevivência.

Um terceiro problema seria encontrado ao tentar definir os limites de uma "ponte escalar" entre níveis diferentes de análise. Por exemplo, no caso em que Cresswell estabeleceu sua análise, foi preciso estabelecer um equilíbrio entre aspectos relativos ao indivíduo (gênero, classe social) e diversas territorialidades, referentes ao poderes público e privado. No caso descrito por Cresswell, mulheres moradoras de rua poderiam ocupar a posição de um dos grupos sociais mais vulneráveis em certas partes da cidade enquanto que, em outras, em certas partes do dia, poderiam ganhar vantagens na apropriação dos espaços públicos frente às estratégias de grupos rivais. Seus domínios poderiam igualmente se expandir em certas horas e dias, e se retrair em outros. Em uma escala ampla, relativa ao ordenamento urbano e a produção, tais grupos se mostrariam incapazes de impedir os avanços da normatização dos espaços públicos ou de alterar os seus valores políticos em qualquer sentido. No entanto, na menor escala, tais grupos podem alcançar um domínio efetivo do território, aproveitando-se das omissões dos grandes agentes e do número de indivíduos desse grupo. Se ocorrer uma repetição desse empoderamento do grupo, ainda que relativo a uma 
pequena área e por um tempo limitado, isso pode acarretar em transformações maiores. Seguindo esse exemplo, isso significa então que a pequena escala não apresenta apenas um detalhamento da grande escala, mas sim um fenômeno de natureza diferente. Consequentemente, é preciso considerar que o grupo, por menor que seja, possa gerar tantos conflitos, estimular tantas sensibilidades diferentes em relação a sua presença no espaço público que os poderes hegemônicos serão levados a considerar os efeitos de suas territorialidades.

\section{CONSIDERAÇÕES FINAIS}

Retomar as formas mais usuais de desenvolvimento na Nova Geografia Cultural segundo um olhar simultaneamente crítico e focado em suas questões exige então reconhecer os riscos da banalidade e do tradicionalismo. Por mais variados que tenham sido os temas e os recortes de lugares e paisagens, o alcance da investigação parecia ser encontrado na admissão de que os poderes hegemônicos se mostram em perfeita oposição aos grupos sociais tradicionais e que a riqueza subjetiva desses últimos mereceria melhor visibilidade e reconhecimento por parte das sociedades modernas. Por essa visão debatida na primeira parte do artigo, seria preciso garantir um certo grau de isolamento para que o grupo social pudesse manter seu lugar de referência e definir o ritmo e o sentido da transformação da cultura. Por vezes, o imobilismo social do grupo parece ser um argumento em favor dessa visão. Porém, tais escolhas contrastam com os ritmos do mundo globalizado, pouco importando a opinião do autor ou os sentimentos dos grupos sociais.

Por exemplo, é preciso considerar que os fenômenos culturais mudam ao longo do tempo e dependem de um jogo de influências mútuas com os domínios político e econômico. As culturas não desaparecem apenas pelo efeito das ações dos Estados ou dos grandes agentes econômicos: muitas delas persistem mesmo nos casos em que outros agentes dominem as suas áreas de referência. Tampouco o isolamento garante a estabilidade e a força coesiva das culturas. Nesse sentido, acreditamos que se mostra mais relevante avaliar os fenômenos culturais em conexão com os demais domínios e a partir de uma visão dinâmica de suas formas, escalas e sentidos.

Ao fazê-lo, é preciso ter o cuidado de destacar que uma mesma área física comporta múltiplas territorialidades, ao mesmo tempo em que cada grupo social e, em última análise, 
cada indivíduo, também revela diversas influências em suas formações e no impacto que tem em relação ao espaço. Nesse processo, por mais interessante e rica que seja uma representação cultural de um grupo social, é preciso que se considere mais do que o seu universo artístico de referência. É preciso destacar com igual importância que, do momento em que esse grupo social se projeta material ou imaterialmente sobre o espaço, tal grupo passa a influenciar e a sofrer influência de outros. Com isso, a dimensão espacial de um grupo social escorado em uma base cultural será sempre uma composição cujo significado de algum modo ultrapassa os limites da subjetividade e da representação artística. Sua existência deve então ser compreendida pelo modo que uma territorialidade significada culturalmente altera e é alterada por outras.

Desse modo, acreditamos que a Geografia Cultural estaria mais apta a responder aos desafios do mundo moderno e aos seus próprios vícios de análise. Também fica mais clara a sua conexão com outros subcampos da Geografia, respondendo a demandas recorrentes nos últimos anos. Se o desafio da tradução relativa à superposição espacial ainda exige maiores aprofundamentos, pelo menos se mostra mais diretamente o caminho a ser seguido no futuro próximo.

\section{REFERÊNCIAS BIBLIOGRÁFICAS}

ATKINSON, D. e COSGROVE, D. Urban Rhetoric and Embodied Identities: City, Nation and Empire at the Vittorio Emanuele II Monument in Rome, 1870-1945. Annals of the Association of American Geographers, v. 88, n. 1, 1998. p. 28-49.

CORREA, R.L. Monumentos, política e espaço. Scripta Nova, vol. IX, nำ183, 2005.

CRESSWELL, T. Embodiment, power and the politics of mobility: the case of female tramps and hobos. Transactions of the Institute of British Geographers, vol.4, n-2, 1999. p. 175192.

CROUCH, D. Places around us: embodied lay geographies in leisure and tourism. Leisure Studies, v.19, nำ2, 2010. p. 63-76.

DUNCAN, J.S.; DUNCAN, N.G. Culture unbound. Environment and Planning A, volume 36, 2004. p. 391-403. 
GOMES, P.C.C. A condição urbana - ensaios de geopolítica da cidade. Rio de Janeiro: Bertrand Brasil, 2000. 304p.

HAESBAERT, R. Da desterritorialização à multiterritorialidade. In: Anais Anais do X Encontro de Geógrafos da América Latina. São Paulo: EGAL, 2005. p. 6774-6792.

HALL, S. A identidade cultural na pós-modernidade. Rio de Janeiro: Guaracira Lopes Louro, 2000. 102p.

HOEFFLE, S.W. Antropologia e Geografia: convergências e divergências históricas. Espaço e Cultura $\mathrm{n}-22$, 2007. p. 6-31.

JACKSON, P. Rematerializing social and cultural geography. Social \& Cultural Geography, Vol. 1, No. 1, 2000. p. 9-14.

LÉVY, J. La géographie culturelle a-t-elle un sens? Annales de géographie $n^{\circ}$ 660-661, v.2, 2008. p. 27-46.

MELLO CORRÊA, A. Não acredito em deuses que não sabem dançar: a festa do Candomblé, território encarnador da cultura. In: CORRÊA, R.L.; ROSENDAHL, Z. Temas sobre cultura e espaço. Rio de Janeiro: edUERJ, 2005. p.141-172.

MITCHELL, D. The end of culture? Culturalism and Cultural Geography in the Anglo-American 'University of Excellence'. Geographische Revue no2, 2000. p.3-17.

MITCHELL, D. There's no such thing as culture: towards a reconceptualization of the idea of culture in geography. Transactions of the Insitute of Brtish Geographers, vol. 20, №1, 1995. p. 102-116.

VALVERDE, R.R.H.F. Largo da Carioca como um cenário: da representação da publicidade à projeção espacial da informalidade. Geousp, no 25, 2009. p. 22-40.

VALVERDE, R.R.H.F. Transformações no conceito de território: competição e mobilidade na cidade. Geousp, n¹5, 2004. pp.119-126.

SACK, R.D. Human territoriality - its theory and history. Cambridge: Cambridge University Press, 1986. 272p. 
SOJA, E. Geografias Pós-Modernas - A reafirmação do espaço na teoria social crítica. Rio de Janeiro: Jorge Zahar, 1993. 324p.

TUAN, Y.F. Espaço e lugar - A perspectiva da experiência. São Paulo: Difel, 1983. 250p. 